\title{
A JUDICIALIZAÇÃO DO DIREITO À SAÚDE NO BRASIL: O RECURSO EXTRAORDINÁRIO No 566.471/RN E AS AÇÕES DE MEDICAMENTOS E CONTRA PLANOS DE SAÚDE
}

\author{
Marcelo Pires Hartwig ${ }^{1}$ \\ Renan Robaina Dias ${ }^{2}$
}

\begin{abstract}
RESUMO: Este trabalho traz um panorama sobre a judicialização do Direito à Saúde no Brasil, através de um enfoque nacional, analisando-se o Recurso Extraordinário no $566.471 / \mathrm{RN}$, que definirá o dever estatal de fornecer medicamentos de alto custo, e de um enfoque regional, analisando-se a afirmação do Direito à Saúde relativamente às ações judiciais de medicamentos e contra planos de saúde nas comarcas de Bagé e Pelotas (RS). Pela análise da jurisprudência do Supremo Tribunal Federal, verificou-se a tendência a uma decisão moderada da questão em apreço. Por fim, constatou-se uma considerável afirmação do Direito à Saúde da população nas comarcas analisadas.
\end{abstract}

Palavras-chave: Direito à Saúde; Direitos Sociais; Judicialização; Medicamentos; Plano de Saúde.

\section{THE JUDICIALIZATION OF THE RIGHT TO HEALTH IN BRAZIL: THE EXTRAORDINARY APPEAL No 566.471 / RN AND THE LAWSUITS FOR MEDICINE AND AGAINST HEALTH INSURANCE PLANS}

\begin{abstract}
This work presents an overview of the judicialization of the Right to Health in Brazil, through a national approach, analyzing Extraordinary Appeal $\mathrm{N}^{\circ} 566.471$ / RN, which will define the State's duty to provide high-cost drugs, and a regional approach, analyzing the affirmation of the Right to Health regarding the lawsuits about health insurance and medicines in the districts of Bagé and Pelotas (RS). It has been found a trend towards a moderate decision by the Brazilian Supreme Court on the issue at hand, and a considerable affirmation of the Right to Health of the population in the counties analyzed.
\end{abstract}

Keywords: Health Insurance; Judicialization; Medicines; Right to Health, Social Rights.

\footnotetext{
${ }^{1}$ Mestrando em Direito pela UFPel. Especialista em Direito Tributário pela PUCRS. Bacharel em Direito pela UFPel. Advogado.

${ }^{2}$ Mestrando em Direito pela UFPel. Especialista em Relações Internacionais pela UNIASSELVI. Bacharel em Direito pela URCAMP. Advogado. Vice-presidente da Comissão da Diversidade Sexual e de Gênero da OAB-RS Subseção de Bagé.
}

Rev. de Direitos Sociais, Seguridade e Previdência Social | e-ISSN: 2525-9865 | Porto Alegre | v. 4 | n. 2 | p. $37-57$ | Jul/Dez. 


\section{INTRODUÇÃO}

O presente trabalho pretende analisar a judicialização do direito à saúde no Brasil, sob o prisma do dever estatal de fornecer medicamentos, especialmente no que se refere às possibilidades e dificuldades no enfrentamento da questão em sede de demanda de caráter geral, o que ocorrerá quando do julgamento do Recurso Extraordinário nº. 566.741/RN. Ademais, analisa-se a quantidade das ações judiciais que envolvem o direito à saúde nas comarcas de Bagé e Pelotas (RS), e se a população dessas cidades, de forma geral, está tendo seu acesso à justiça assegurado relativamente ao direito à saúde.

Busca-se fazer a análise através de dois enfoques principais, um nacional e outro regional, sendo eles, respectivamente: a) o dever do fornecimento de medicamentos pelo Estado, em sede de demanda de caráter geral, o que ocorrerá quando do julgamento do Recurso Extraordinário $\mathrm{n}^{\circ}$. 566.741/RN; b) o volume de ações judiciais de medicamentos e contra planos de saúde nas comarcas de Bagé e Pelotas (RS).

A temática se mostra relevante, tanto do ponto de vista social quanto jurídico. É de conhecimento geral a insuficiência do fornecimento de medicamentos por parte da rede pública de saúde, seja pela falta de medicamentos em estoque ou pela não inclusão de determinado medicamento em lista elaborada em sede de política pública de saúde. Relativamente aos planos de saúde, é notória a dificuldade enfrentada pelos conveniados quando da necessidade de cobertura do plano a um procedimento de caráter mais oneroso.

Para se obter um panorama da judicialização do direito à saúde no Brasil, pergunta-se qual o posicionamento que está em consonância com a Constituição Federal de 1988, com relação ao fornecimento de medicamentos de alto valor pelo Estado? Com base nessa premissa, qual poderá ser o entendimento do Supremo Tribunal Federal no julgamento do Recurso Extraordinário no n $^{\circ} 66.471 / \mathrm{RN}$ ? Por fim, a população das cidades de Bagé e Pelotas, as duas maiores comarcas da região sul do Rio Grande do Sul, estão tendo seu direito à saúde assegurado?

Para a realização do estudo será aplicado o método dedutivo, partindo-se das premissas e conceitos presentes nos conhecimentos disponíveis, obtidos através de análise bibliográfica e documental. Como método auxiliar, realizar-se-á pesquisa empírica através da ferramenta de busca do sítio do Tribunal de Justiça do Rio Grande do Sul na internet (filtragem por comarca, data e palavras-chave), e do requerimento de dados aos órgãos públicos como a Defensoria Pública do Estado e a Procuradoria Geral do Estado do Rio Grande do Sul. 


\section{O DIREITO À SAÚDE NA CONSTITUIÇÃO FEDERAL DE 1988}

\subsection{O ESTADO DEMOCRÁTICO DE DIREITO}

No decorrer da história, o Estado brasileiro apresentou diferentes formatos, sendo adotado, no momento atual, o Estado Democrático de Direito, que deve, ainda que brevemente, ser analisado de modo a que se possa verificar o papel do Poder Público em relação ao dever prestacional decorrente do Direito à Saúde no atual cenário constitucional do país.

O Estado Democrático de Direito consiste na criação de um conceito novo, que vai além da mera união formal dos conceitos do Estado Democrático e do Estado de Direito, tendo como um de seus principais elementos o da transformação do status quo (SILVA, 1998,

p. 7), sendo sua principal tarefa a superação das desigualdades e a instauração de um regime efetivamente democrático (SILVA, 1998, p. 24). A referida tarefa pode ser realizada por meio da aplicação dos princípios do Estado Democrático de Direito, quais sejam: i) vinculação do Estado a uma Constituição como garantia jurídica; ii) organização democrática da sociedade; iii) sistema de direitos fundamentais individuais e coletivos; iv) justiça social; v) igualdade (formal e material); vi) novo relacionamento entre os Poderes, de modo a buscar os fins constitucionais, vii) legalidade; viii) segurança jurídica (STRECK; MORAIS, 2013, p. 207).

A Constituição Federal de 1988 adotou a forma de Estado Democrático de Direito de forma expressa, como se nota em seu art. $1^{\circ}$, caput, que determina ser o Brasil uma República Federativa, constituindo-se em Estado Democrático de Direito. Verificam-se, assim, as seguintes características: Estado Federado (forma de Estado), República (forma de governo) e Democracia (regime de governo). Para o presente estudo, cumpre tratar das duas últimas.

Sobre a República, entende Fábio Konder Comparato (2005, p. 2-3) que sua essência encontra-se na distinção entre o interesse de cada um em particular e o bem comum de todos, com a exigência de que este se sobreponha sempre àquele. Defende, também, que entre as instituições básicas do regime republicano está o respeito integral aos direitos humanos (incluindo neste tópico os direitos econômicos, sociais e culturais).

Acerca da Democracia, frisa-se que a possibilidade para o exercício pleno da participação popular democrática encontra-se nas melhores condições de vida dos cidadãos, bem como na igualdade (formal e material) entre eles (MASSAÚ; KÖLLING, 2011, p. 16). 


\subsection{O DIREITO SOCIAL À SAÚDE}

O Direito à Saúde, direito social previsto no art. $6^{\circ}$ da atual Constituição pátria, que lhe conferiu o status de direito fundamental, decorre dos princípios do Estado Democrático de Direito, de modo que sua promoção implica na realização do ideal dessa forma de Estado.

Além do art. $6^{\circ}$, o Direito à Saúde encontra referência nos arts. 196 a 200 da Constituição Federal, podendo ser definido como um bem jurídico relacionado de forma indissociável com a vida, indo além da mera ausência de doenças ou enfermidades, referindose, também, ao bem-estar físico, social e mental (MASSAÚ; KÖLLING, 2011, p. 8). Tal definição, por óbvio, abrange o direito do cidadão ao recebimento de medicamentos por parte do Estado, que possui, em contrapartida, o respectivo dever prestacional.

Apesar da sua importância, os Direitos Sociais, na prática, enfrentam um período de crise, muito em função do impacto da difícil situação da economia (SARLET, 2015, p. 463464). Infelizmente, o Direito à Saúde não constitui uma exceção a essa afirmação. Carecem, portanto, de efetividade, cuja busca tem se revelado questão espinhosa.

Na sequência, propõe-se analisar as principais questões atinentes ao Direito à Saúde, especialmente no que toca à sua eficácia, tendo como foco a prestação de medicamentos.

\section{O DEVER ESTATAL DE FORNECER MEDICAMENTOS}

\subsection{A DIMENSÃO POSITIVA DO DIREITO A MEDICAMENTOS}

Na conhecida classificação dos direitos fundamentais em direitos de defesa (negativos) e direitos a prestações (positivos) (SARLET, 2007, p. 7-8), é certo que o direito ao recebimento de medicamentos enquadra-se na segunda hipótese, representando um alto custo para os cofres públicos, mais elevado que o custo atinente os direitos negativos, eis que os gastos necessários para a garantia destes (especialmente os de manutenção das instituições públicas), existem também para os direitos sociais, que abrangem, além disso, o elevado custo decorrente de seu viés majoritariamente prestacional.

A implementação do fornecimento de medicamentos, nos termos do art. 196 da Constituição Federal, se dá por meio de políticas públicas, tarefa que depende da atuação dos Poderes Legislativo e Executivo e da sociedade civil (SILVA, 2008, p. 595). Tal constatação gera consequências de difícil superação, entre elas, as muitas divergências no que se refere à 
atuação do Poder Judiciário, consoante será analisado no tópico seguinte.

\subsection{O MÍNIMO EXISTENCIAL E A RESERVA DO FINANCEIRAMENTE POSSÍVEL}

Em que pese o alto custo dos Direitos Sociais, há que se respeitar a ideia do mínimo existencial, assim entendido como o mínimo de condições de vida que o cidadão necessita para sobreviver, sendo o Estado sempre obrigado a respeitar esse patamar mínimo.

Questão também correlata à aferição da extensão do dever estatal é a ideia da reserva do financeiramente possível. Surgido na jurisprudência alemã, esse conceito diz respeito ao que o cidadão pode exigir da administração pública levando em consideração outros interesses da coletividade (DOS SANTOS, 2016, p. 166). Embora não prevista na Constituição pátria, o instituto está consagrado no art. $2^{\circ}$ do Pacto Internacional sobre Direitos Econômicos, Sociais e Culturais, ratificado pelo Brasil através do Decreto $n^{\circ}$. 591/92.

A existência de necessidades básicas não satisfeitas é um forte argumento para a busca de sua satisfação, seja através de políticas públicas, seja através da via judicial. Nesse contexto, o mínimo existencial e a reserva do possível representam lados opostos, no âmbito dos quais transita a judicialização do direito a medicamentos.

\subsection{A JUDICIALIZAÇÃO DO DIREITO AMEDICAMENTOS}

Questão tormentosa é a possibilidade de obtenção, na via judicial, da concessão de determinada prestação referente ao Direito à Saúde, especialmente quando não contemplada em política pública, o que, apesar de não se revelar medida juridicamente inviável, precisa ter seus limites delineados, a fim de não se chegar a uma situação de descontrole.

É importante ressaltar que, para a maior parte das situações, o legislador realiza ponderações em abstrato, resolvendo, de modo prévio, os possíveis conflitos existentes. $\mathrm{Na}$ generalidade dos casos, são estas decisões, consubstanciadas nas políticas públicas, que deverão prevalecer, cedendo apenas diante de casos extraordinários (ÁVILA, 2009, p. 5-6).

Em qualquer caso, verificam-se dificuldades de difícil superação, que não se resumem ao simples conflito entre os direitos à vida e a saúde, de um lado, e a separação dos poderes, a necessidade de previsão orçamentária para a realização, despesa e a reserva possível, de outro. Em verdade, o que se verifica é uma colisão entre os direitos à vida e a saúde de um (ou de alguns) com os direitos à vida e a saúde de outro (ou de outros). Esta constatação, sem dúvidas, 
torna a questão ainda mais complexa (BARROSO, 2015, p. 4).

Diante deste cenário, cumpre serem buscados critérios que permitam uma solução juridicamente adequada, superando as barreiras acima referidas.

\subsection{A PONDERAÇÃO DO DIREITO À SAÚDE}

Inicialmente, cumpre definir a espécie normativa do direito à saúde. As normas, como amplamente difundido na doutrina, são regras ou são princípios, cuja distinção pode ser percebida através do conceito de cada uma das espécies.

Proposta de diferenciação amplamente difundida é a teoria de Robert Alexy. Afirma o autor alemão que as regras são mandamentos definitivos, exigindo um cumprimento pleno, ao passo que os princípios são mandamentos de otimização (ou mandamentos para serem otimizados) (MOREIRA, 2014, p. 14), cuja realização deve ocorrer na maior medida possível diante das possibilidades fáticas e jurídicas existentes (SILVA, 2006, p. 27).

É sabido que há intensos debates doutrinários sobre o tema, havendo propostas diversas das acima referidas, como a bem elaborada Teoria dos Princípios de Humberto Ávila (2016, p. 102). Sem olvidar das diferenças doutrinárias sobre o assunto, revela-se suficiente, para fins do presente estudo, a ideia geral de que as regras exigem um cumprimento pleno, enquanto os princípios, para serem aplicados, exigem a aplicação da ponderação.

O Direito à Saúde pode aparecer tanto como regra quanto como princípio. No caso das políticas públicas já existentes, nas quais conste, por exemplo, que determinado medicamento deva ser fornecido, trata-se de uma regra, que deverá ser aplicada plenamente, justificando, inclusive, ingresso de demanda judicial na hipótese de seu descumprimento. O Direito à Saúde, em uma perspectiva mais geral, ou seja, fora dos casos já disciplinados por meio de políticas públicas, revela-se como um princípio (MOREIRA, 2014, p. 14-15), eis que se refere a um estado ideal de coisas a ser promovido (ÁVILA, 2009, p. 6). Nesses casos, deverá ser realizada ponderação que leve em conta uma série de fatores, como a competência orçamentária, a reserva do possível, a separação dos poderes e o direito à saúde alheio. A aplicação do Direito à Saúde como sendo da espécie regra, em última análise, negaria a existência de políticas públicas, que pressupõem escolhas e alocações orçamentárias, indo de encontro, inclusive, ao art. 196 da Constituição Federal, que prevê a garantia do direito à saúde mediante políticas sociais e econômicas (MOREIRA, 2014, p. 10-11).

Antes de adentrar nos critérios da ponderação, é necessário definir o âmbito de 
proteção do Direito à Saúde. Tendo em vista tratar-se de princípio, é necessário diferenciar o conteúdo de proteção prima facie do definitivo. Virgílio Afonso da Silva (2006, p. 34-35) refere que a proteção prima facie inclui toda ação, estado ou posição jurídica que diga respeito a determinado princípio. Trata-se de definição propositadamente aberta, que não redunda em um direito absoluto, eis que a proteção prima facie é passível de restrição, o que poderá ocorrer mediante intervenção constitucionalmente fundamentada (SILVA, 2006, p. 35).

Visto isso, é possível, então, passar ao estudo da forma como pode se dar a restrição ao Direito à Saúde, revelando-se imperiosa uma análise da proporcionalidade, apontada como a principal forma de controle das restrições aos direitos fundamentais (SILVA, 2006, p. 36). A proporcionalidade apresenta, de pronto, dificuldade em termos de terminologia. Humberto Ávila (1999, p. 169-170) defende a ideia de que o dever de proporcionalidade não é nem regra, nem princípio, mas um postulado normativo aplicativo. Por outro lado, Virgílio Afonso da Silva (2002, p. 24-26) entende que a proporcionalidade deve ser classificada como regra, uma vez que sua aplicação se dá pela subsunção. A fim de evitar confusão terminológica, será empregada, na sequência, a expressão "dever de proporcionalidade".

O dever de proporcionalidade estrutura-se em elementos, dividindo-se em adequação, necessidade e proporcionalidade em sentido estrito. Uma medida pode ser considerada adequada quando o meio escolhido possui aptidão para alcançar o resultado almejado; necessária, quando, comparada com as outras medidas possíveis, for a menos gravosa em relação aos direitos envolvidos; proporcional em sentido estrito, quando não implicar em excessiva restrição dos direitos envolvidos. (ÁVILA, 1999, p. 172). Tais elementos devem ser aplicados através da ordem acima referida (SILVA, 2002. p. 34), cabendo, portanto, a análise da proporcionalidade em sentido estrito (último elemento do dever de proporcionalidade) apenas nos casos mais complexos, devendo a medida adotada ter sido, previamente, considerada adequada e necessária (SILVA, 2002, p. 34-35).

\section{O RECURSO EXTRAORDINÁRIO No.566.471/RN}

\subsection{BREVES CONSIDERAÇÕES SOBRE O PROCESSO}

No dia 24 de outubro de 2007, ao proferir a decisão de Repercussão Geral no Recurso Extraordinário $n^{\circ}$. 566.471/RN, o Supremo Tribunal Federal, sob a relatoria do Ministro Marco Aurélio, reconheceu a existência de repercussão da questão a respeito da controvérsia sobre a 
obrigatoriedade de o Poder Público fornecer medicamento de alto custo. Trata-se do leading case do tema de repercussão $\mathrm{n}^{\circ}$. 6: "dever do Estado de fornecer medicamento de alto custo a portador de doença grave que não possui condições financeiras para comprá-lo”. Na sequência, passa-se a analisar se uma decisão de caráter geral é suficiente e/ou adequada para a solução do problema.

\subsection{LIMITES DE UMA DECISÃO PROFERIDA EM DEMANDADE CARÁTER GERAL}

Em estudo sobre tema da judicialização do fornecimento de medicamentos, Luís Roberto Barroso (p. 28) pretende oferecer parâmetros para racionalizar e uniformizar a atuação do Poder Judiciário em demandas desta natureza, tanto as de natureza individual como de natureza coletiva.

No que tange as demandas individuais, o autor sustenta a ideia de que "a atuação jurisdicional deve ater-se a efetivar a dispensação dos medicamentos constantes das listas elaboradas pelos entes federativos" (BARROSO, s/d, p. 29). O posicionamento justifica-se pelo fato de que os Poderes Legislativo e Executivo, ao menos presumivelmente, quando da definição dos medicamentos a serem fornecidos, avaliaram as necessidades prioritárias e os recursos financeiros disponíveis, a partir de uma visão ampla e global, não individualizada.

Por outro lado, o autor defende que "a alteração das listas pode ser objeto de discussão no âmbito de ações coletivas" (BARROSO, s/d, p. 31). Por este raciocínio, poderá o Judiciário, no âmbito das ações coletivas ou das ações abstratas de controle de constitucionalidade, rever lista elaborada por algum ente federativo e, verificando grave desvio de avaliação, decidir pela inclusão de medicamento não previsto. Isso porque demandas desse tipo exigiriam um exame do contexto geral das políticas públicas em análise (inclusive as questões relacionadas à alocação de recursos) e seu efeito erga omnes confere igualdade de tratamento e possibilidade de planejamento estatal (BARROSO, s/d, p. 32-33). O autor apresenta, ainda, critérios complementares, quais sejam: só poderão ser incluídos medicamentos de eficácia comprovada; deverá optar-se por substâncias disponíveis no Brasil; deverá optar-se por medicamento genérico (de menor custo); deverá considerar-se a circunstância de ser o medicamento indispensável para a manutenção da vida (BARROSO, s/d, p. 33-35).

De acordo com a proposta de Luís Roberto Barroso, deveria ser negado o fornecimento de medicamentos nesta hipótese, eis que, em demanda individual, não poderia o Poder Judiciário realizar tal determinação, por estar o medicamento fora do âmbito das políticas 
públicas elaboradas pelos demais poderes. Apesar de não parecer solução juridicamente impensável, sua aplicação para todo e qualquer caso não se mostra compatível com a ordem constitucional brasileira, que reconhece força normativa a todas as normas constitucionais, sobre o que já se referiu neste estudo. Neste sentido, ainda que apenas em casos excepcionais, é possível, via processo individual, a obtenção de medicamentos não previstos nas listas decorrentes das políticas públicas de saúde.

Será necessária então a realização de ponderação com uma série de valores conflitantes, chegando-se, assim, à solução do caso. Esta ponderação, todavia, necessita de uma análise do caso concreto, de modo que, considerando os direitos e princípios em conflito, se possa buscar uma solução que compatibilize os bens em jogo (SARLET, 2007, p. 14).

Por outro lado, menos desejável ainda seria uma solução, de caráter geral e com efeitos erga omnes, no sentido de serem devidos medicamentos de alto custo por parte do Poder Público. Um julgamento neste sentido esvaziaria de sentido até mesmo a existência de políticas públicas, atribuindo características de norma do tipo regra ao direito a medicamentos, que seria devido em qualquer caso.

O que se pode cogitar seria uma decisão, por assim dizer, intermediária, utilizando- se, para as demandas individuais, os critérios complementares propostos por Luís Roberto Barroso para o caso das ações coletivas. Acredita-se que, assim, seria possível uma diminuição da quantidade de demandas individuais e uma melhor orientação para a atuação dos julgadores e da administração pública, no que se revela a grande utilidade do raciocínio elaborado. Todavia, pretender, em demanda de caráter geral, a completa resolução da problemática do direito a medicamentos parece ser objetivo utópico - o que não obsta a busca da melhor solução para a questão.

\subsection{UMA TENTATIVA DE PROJEÇÃO DA DECISÃO A SER TOMADA PELO SUPREMO TRIBUNAL FEDERAL}

Para que se possa pensar em uma projeção da posição que será tomada pelo Supremo Tribunal Federal quando do julgamento do Recurso Extraordinário n ${ }^{\circ}$. 566.741/RN, é preciso fazer uma investigação do histórico de decisões do Tribunal envolvendo o Direito à Saúde, especialmente a questão do fornecimento de medicamentos.

Há valiosos estudos a esse respeito, entre os quais, o de Otávio Balestra Neto (2015), que abordou a evolução da jurisprudência dos Tribunais Superiores (Superior Tribunal de 
Justiça e Supremo Tribunal Federal) no que se refere ao Direito à Saúde. Menciona o autor que a judicialização da saúde, no Brasil, é fenômeno recente, tendo como marco o cenário jurídico instalado através da Constituição Federal de 1988 (NETO, 2015, p. 89). Seu estudo, portanto, pretendeu abordar o período posterior ao surgimento da atual Constituição (NETO, 2015, p. 93). O autor identifica a existência de três fases distintas no posicionamento da jurisprudência dos Tribunais Superiores no que tange ao Direito à Saúde.

Na primeira fase, cujo surgimento se deu no início da década de 1990, a jurisprudência majoritária seguia o entendimento da impossibilidade de interferência do Poder Judiciário nas políticas públicas de saúde (NETO, 2015, p. 95). A segunda fase, iniciada no ano de 2000, foi marcada por uma virada de entendimento, com a identificação da fundamentalidade material do direito à saúde como decorrência direta da dignidade da pessoa humana, sendo acolhidos, de forma indiscriminada, os pedidos de prestações relacionadas ao Direito à Saúde. Por parte do Supremo Tribunal Federal, cumpre referir o Recurso Extraordinário no. 195.192/RS e o Agravo Regimental no Recurso Extraordinário no. 271.286/RS como julgados elucidativos desta nova posição (NETO, 2015, p. 97). Ainda na década de 2000, surgiu a terceira fase, representada por uma superação da ideia de que o direito à saúde representaria um direito irrestrito a toda e qualquer prestação a ele relacionada. Os casos concretos passaram a ser analisados de forma mais minuciosa, levando-se em consideração questões de ordem técnica, o que gerou decisões que negaram pleitos de usuários do SUS que estariam em desacordo com as políticas públicas de saúde. O Supremo Tribunal Federal proferiu significativos julgados nesse sentido, quais sejam: Suspensão de Segurança $n^{\circ}$. 3.073 e Agravo Regimental na Tutela Antecipada $n^{\circ} .175$.

Feita esta apuração da evolução jurisprudencial, é importante buscar os elementos já disponíveis no caso específico que se pretende analisar. Conforme matéria veiculada no site oficial do Supremo Tribunal Federal, alguns Ministros já manifestaram seu posicionamento. Na sessão do dia 28 de setembro de 2016, o relator, Ministro Marco Aurélio, trouxe a seguinte proposta de decisão para análise do Plenário (Supremo Tribunal Federal - Notícias STF, p. 1):

O reconhecimento do direito individual ao fornecimento, pelo Estado, de medicamento de alto custo, não incluído em Política Nacional de Medicamentos ou em Programa de Medicamentos de Dispensação em Caráter Excepcional, constante de rol dos aprovados, depende da demonstração da imprescindibilidade - adequação e necessidade -, da impossibilidade de substituição do fármaco e da incapacidade financeira do enfermo e da falta de espontaneidade dos membros da família solidária 
em custeá-lo, respeitadas as disposições sobre alimentos dos artigos 1.694 a 1.710 do Código Civil, e assegurado o direito de regresso.

Tanto o histórico das decisões do Tribunal sobre o tema quanto as propostas já apresentadas no caso concreto indicam um caminho semelhante, qual seja, uma posição moderada, no sentido de que a concessão de medicamento de alto custo não previsto em política pública não configura a regra, mas sim a exceção, que, para sua ocorrência, devem estar presentes uma série de requisitos. Acredita-se que uma decisão nesse sentido irá "apenas", e isso já representa um grande alento, acarretar em uma diminuição dos processos sobre o tema e uma maior objetividade e racionalidade nas decisões judiciais, gerando, inclusive, uma diminuição no tempo de duração dos processos.

\section{O ACESSO À JUSTIÇA E O DIREITO À SAÚDE}

Como já visto anteriormente, o conceito de saúde aqui trabalhado é mais abrangente do que a mera ausência de doença física. No mesmo sentido, trabalha-se com a ideia de acesso à justiça não se limita ao ingresso formal de uma ação judicial pelo autor, mas é aqui entendido como o acesso aos benefícios jurídicos em geral no nível legislativo e administrativo, além do acesso ao Judiciário, com a garantia de uma solução justa (VENTURA et al, 2010, p. 9).

No entanto, a busca pela via judicial para garantir o fornecimento de medicamentos ainda se constitui numa das principais ferramentas utilizadas pelo brasileiro, em especial pela população de baixa renda, pois a despesa com medicamentos representa a de maior peso no gasto total das famílias com saúde, impactando no orçamento, principalmente entre os mais pobres (IBGE, 1998; IBGE, 2004). Conforme aponta Ventura (SZWARCWALD et al., 2004, apud VENTURA et al, 2010), a Pesquisa Mundial da Saúde, realizada em 2003, e a Avaliação da Assistência Farmacêutica no Brasil, realizada em 2004, mostram um acesso - público e privado - de, respectivamente, $87,0 \%$ e $89,6 \%$ dos medicamentos prescritos na última consulta. Contudo, em ambos os estudos, a falta de recursos financeiros constou como a principal alegação entre os cidadãos que não conseguiram adquirir seus medicamentos $(55,0 \%$ e 62,8\%, respectivamente).

Mas a busca da tutela judicial nem sempre é sinônimo da efetiva afirmação do direito à saúde. Inúmeras variáveis influenciam na resposta para esta indagação, necessitando-se separá-la em duas situações concretas, que refletem a desigualdade social brasileira: a 
população de baixa renda, quando demanda em juízo, normalmente o faz contra o Sistema Único de Saúde (SUS), uma vez que não possui condições de contratar plano de saúde privado - e o faz sob o benefício da Assistência Judiciária Gratuita (AJG), comumente através da Defensoria Pública. Diferentemente das pessoas com um maior poder aquisitivo, sejam servidores públicos, profissionais liberais ou do setor privado, e que, diante da negativa do plano de saúde contratado em arcar com determinado tratamento terapêutico e/ou medicamentoso, demanda contra o plano privado ao qual é conveniado - seja por procurador público ou privado, com ou sem AJG.

Para se ter um retrato do acesso à justiça na afirmação do direito à saúde, realizou-se pesquisa empírica através do sítio do Tribunal de Justiça do Rio Grande do Sul, na ferramenta de busca por jurisprudências. Como estratégia para a melhor compreensão do fenômeno da judicialização da saúde, o estudo buscou abordagens de análise quantitativa e qualitativa. Seu objetivo é identificar variáveis no banco de dados do Poder Judiciário que possam evidenciar características das demandas judiciais contra os planos de saúde. A filtragem dos resultados foi feita por palavras-chave ("plano de saúde"), fazendo-se o recorte temporal pela análise dos anos de 2015, 2016 e 2017, buscando por decisões julgadas e publicadas entre os dias 01 de janeiro a 31 de dezembro de cada ano. Para se ter um parâmetro de comparação, selecionou-se as duas maiores comarcas do sul do Estado do Rio Grande do Sul: Bagé e Pelotas.

\subsection{AS AÇÕES CONTRA PLANOS DE SAÚDE NAS COMARCAS DE BAGÉ E PELOTAS}

A amostra extraída limita-se às decisões de $2^{\mathrm{a}}$ instância, não considerando as decisões do primeiro grau de jurisdição. Assim, num primeiro momento, buscou-se saber o número total de ações direcionadas contra planos de saúde nas duas comarcas citadas, especificando-se, a título de conhecimento, a peça processual utilizada.

Dados de Bagé: 


\section{5 - 23 resultados}

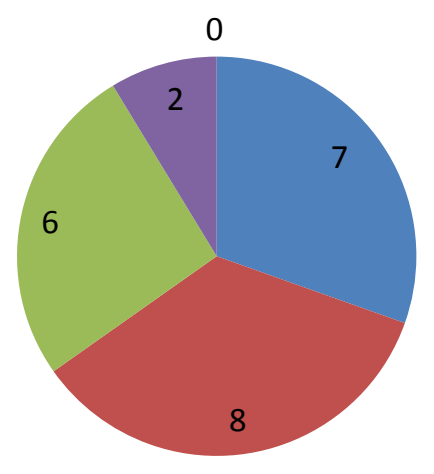

Agravo de Instrumento

Apelação

Recurso Inominado

Embargos de Declaração

Recurso Especial
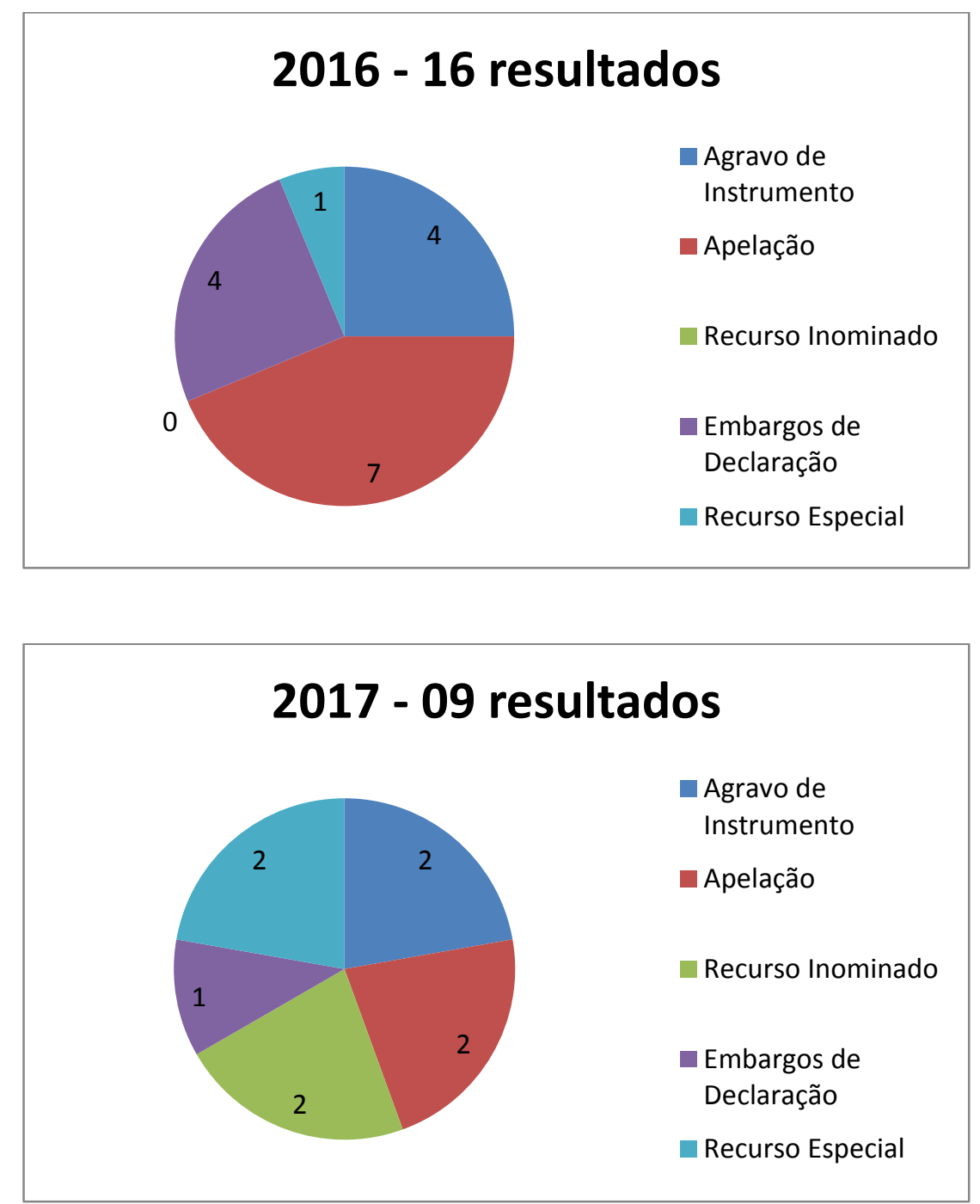

Dados de Pelotas: 

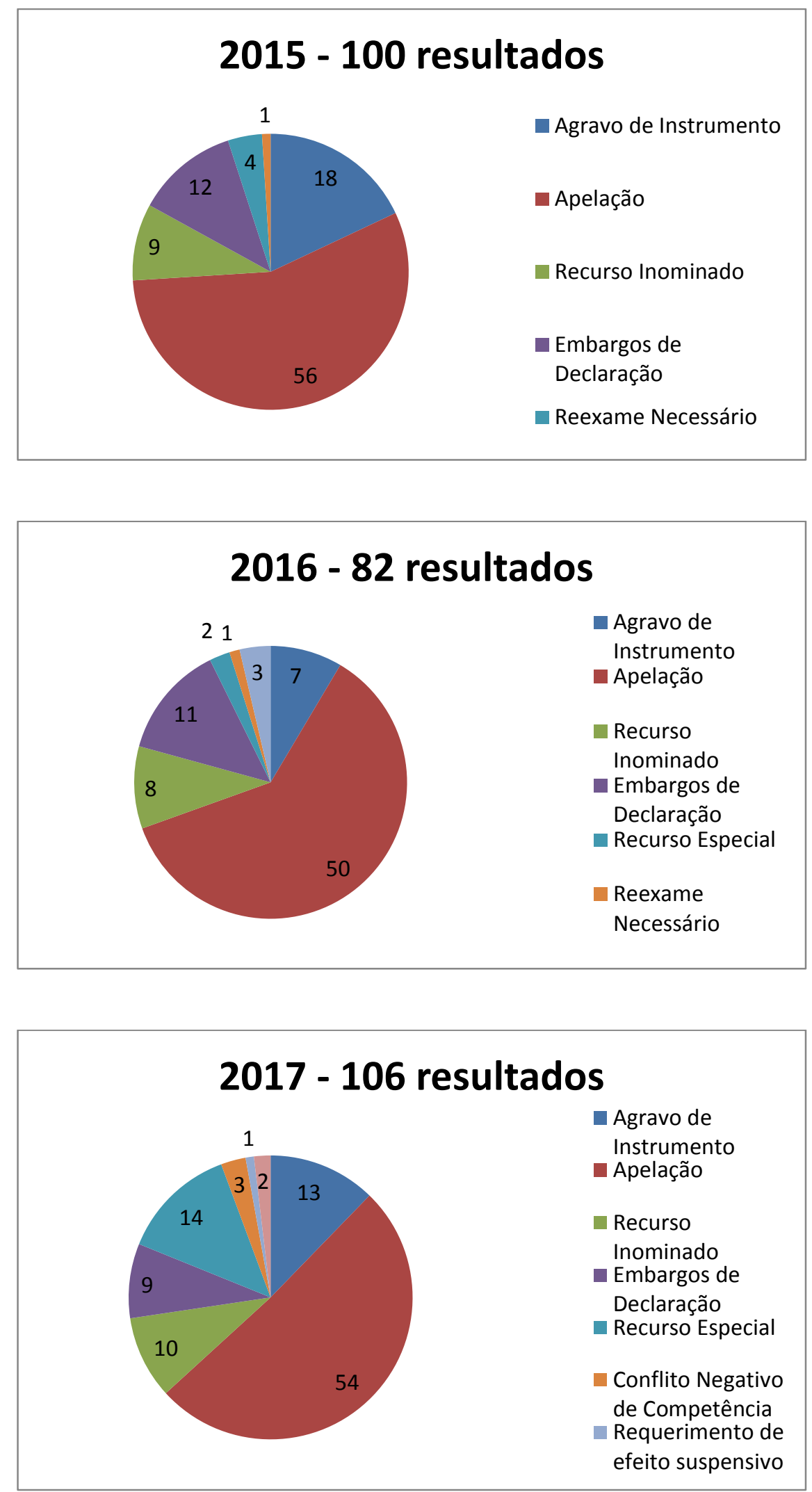

Segundo passo, selecionaram-se as principais causas de pedir de cada ação. Diante da variedade de pedidos formulados, priorizaram-se os quatro mais comuns (reparação de danos; 
inclusão de dependentes; restituição de valores; e obrigação de fazer). Na categoria "outros" foram incluídos aqueles casos em que não se podia denotar o assunto principal através da leitura do corpo da ementa; os casos em que as palavras-chave apareciam por constituírem pedidos secundários (ex.: ação de divórcio onde o/a ex-cônjuge pede para ser mantido como dependente no plano de saúde do titular).

Dados de Bagé:

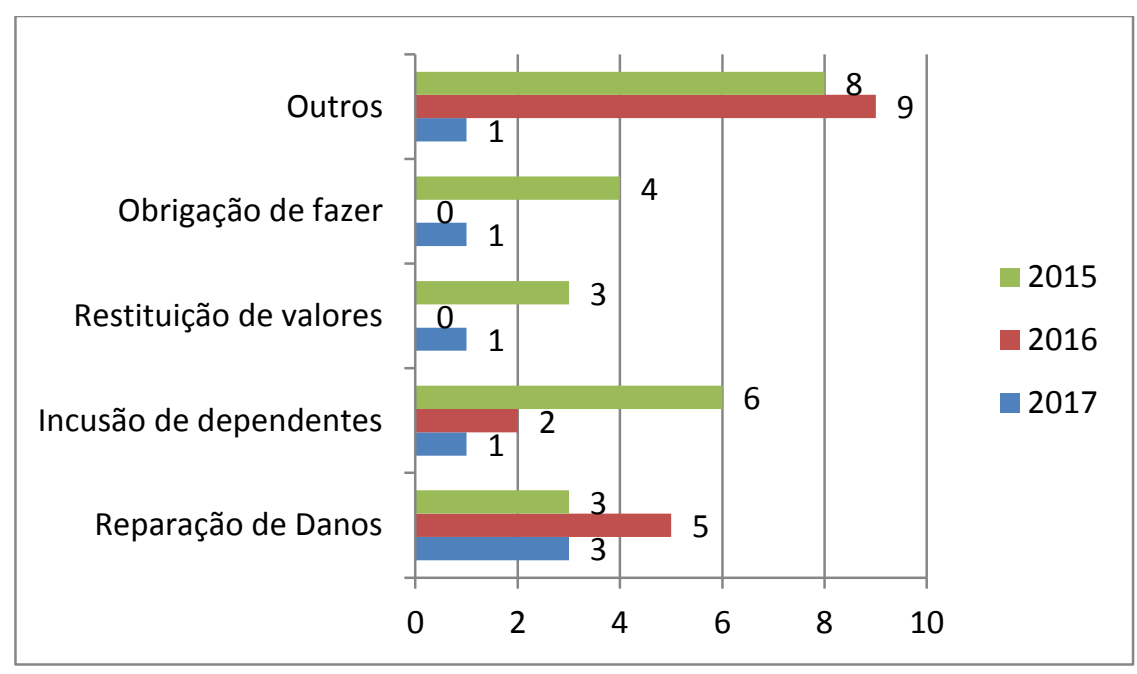

Dados de Pelotas:

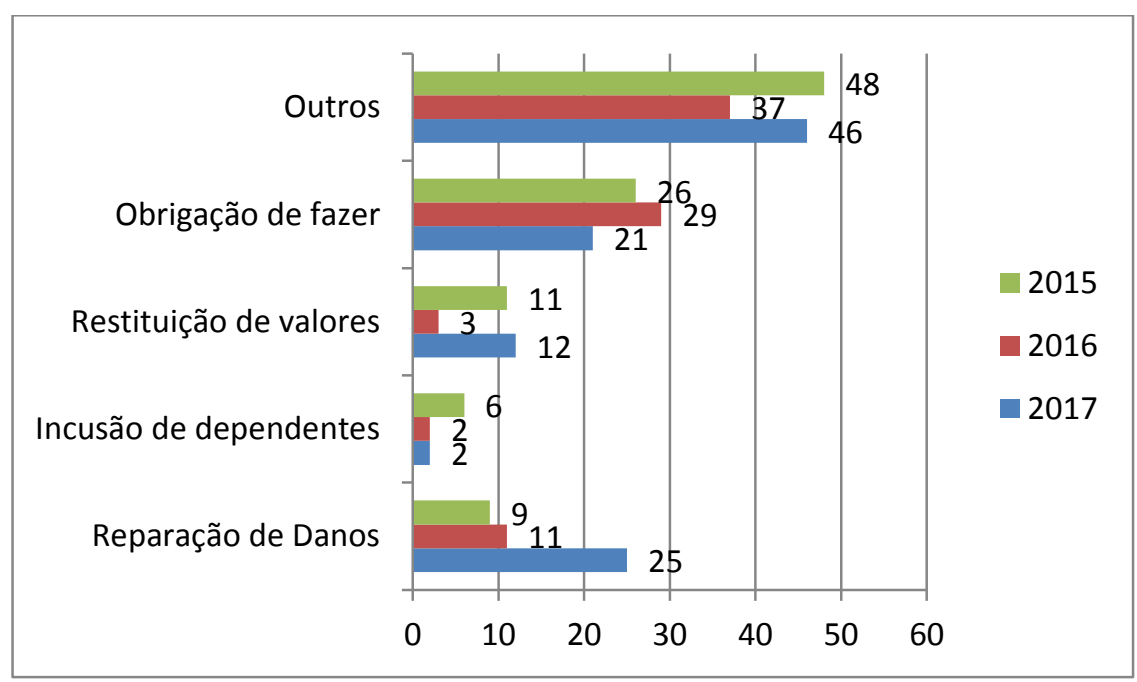

Por fim, buscou-se saber quantas decisões do total de cada período foram favoráveis para o autor da ação (aqui consideradas as decisões procedentes e as parcialmente procedentes). Não foram levados em consideração os casos em que pela leitura da ementa não foi possível 
descobrir quem a decisão favoreceu (em sua maioria, classificados na categoria “outros”).

Dados de Bagé:

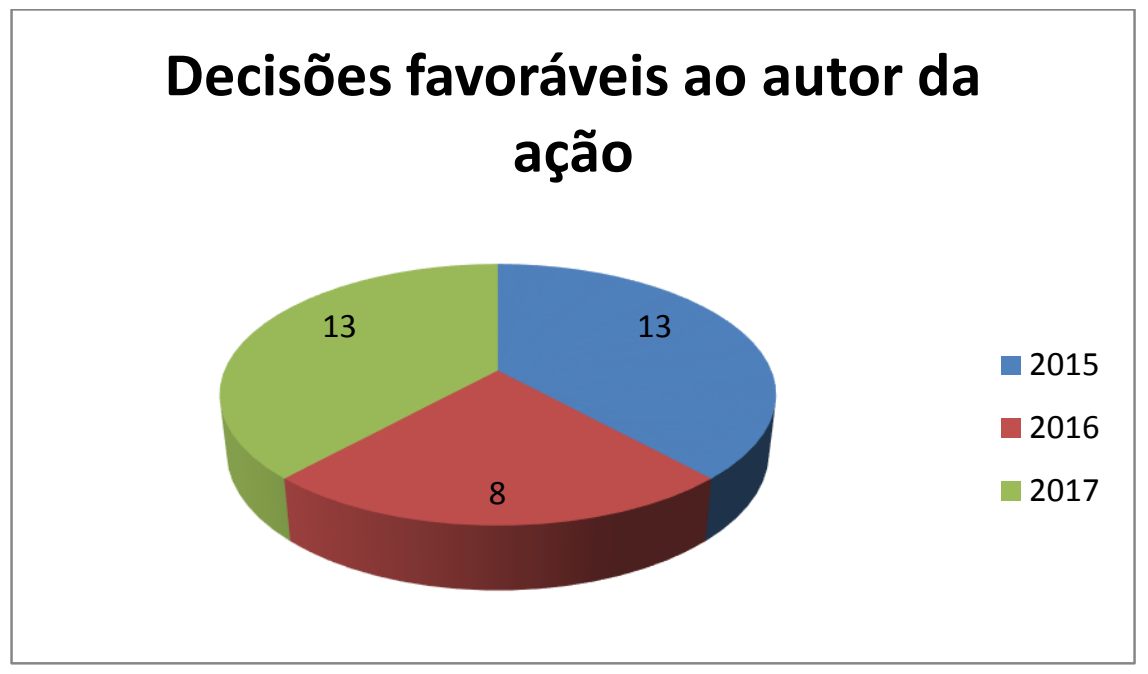

Dados de Pelotas:

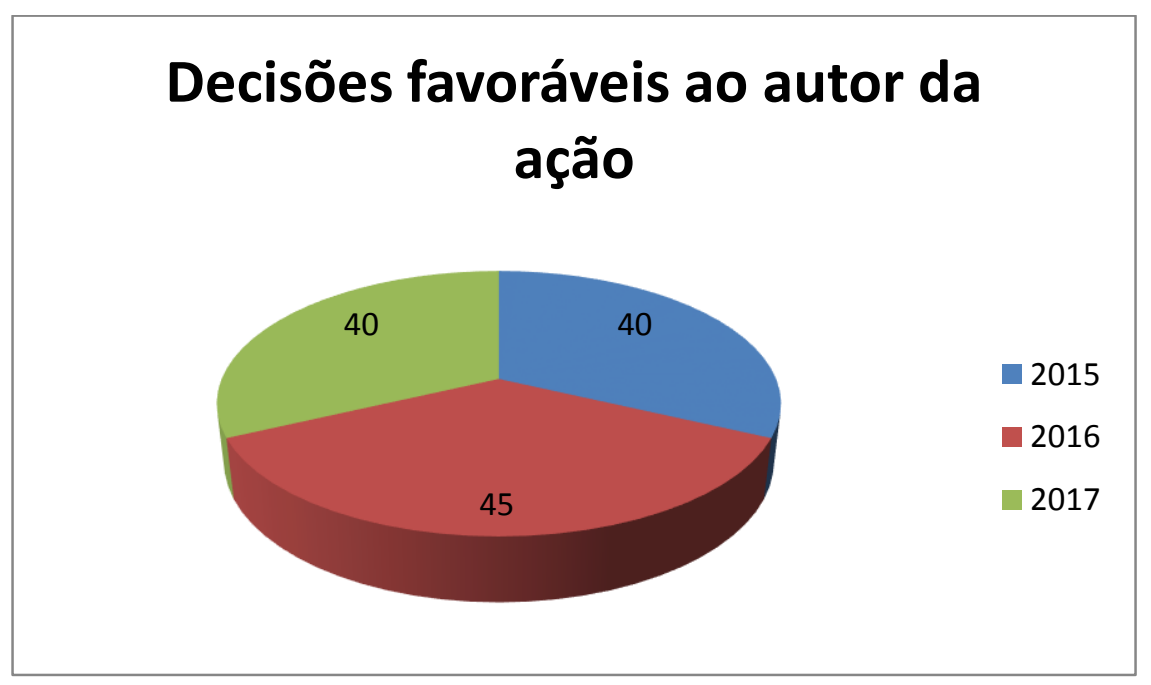

\subsection{AS AÇÕES DE MEDICAMENTOS NAS COMARCAS DE BAGÉ E PELOTAS}

Com relação às ações judiciais de medicamentos, como já mencionado, a Defensoria Pública constitui poderosa ferramenta de acesso à justiça da população carente. Porém, o sítio do TJ-RS não mostra resultados de busca utilizando-se as palavras-chave "Defensoria Pública + medicamentos". Buscou-se então outra forma de obtenção de dados para a análise pretendida.

Em contato com a Defensoria Pública Estadual (DPE) da comarca de Pelotas, foram 
solicitados os dados relativos ao número total de ações ajuizadas por este órgão, o número de ações de medicamentos, bem como suas decisões (se favoráveis ou desfavoráveis), nas comarcas de Bagé e Pelotas, nos anos de 2015, 2016 e 2017. No entanto, os dados enviados pelo órgão aos autores, por $e$-mail, foram os seguintes:

\begin{tabular}{|c|c|}
\hline \multicolumn{2}{|c|}{ Quantidade de Ações de Medicamentos ajuizadas pela DPE no RS nos últimos anos } \\
\hline 2015 & 669 ações \\
\hline 2016 & 6.933 ações \\
\hline 2017 & 9.626 ações \\
\hline 2018 & 417 ações \\
\hline
\end{tabular}

Em anexo aos dados, havia a explicação de que o total indicado é o número de petições iniciais aprovadas em pastas de assunto CNJ "Fornecimento de Medicamentos", podendo existir petições em pastas classificadas incorreta ou insuficientemente, e que, portanto, não constariam neste total. O sistema de informação do qual os dados foram extraídos foi implantado a partir de 2015, gradualmente - apenas a partir de março de 2017 os dados contemplam todo o Estado -, o que explica a discrepância entre os números de 2015 e dos dois anos seguintes (DPE, 2018).

A DPE não informou o número discriminado de ações nas comarcas de Bagé e Pelotas, tampouco o conteúdo das decisões, o que prejudicou a conclusão da pesquisa com relação às ações de medicamentos nas duas comarcas. Assim, como forma de complementação de dados, foi solicitado à Procuradoria Geral do Estado do Rio Grande do Sul (PGE) o número de ações de medicamentos sob sua atuação, no mesmo período pesquisado. Em resposta, a PGE respondeu, por e-mail, com as seguintes informações:

\begin{tabular}{|c|c|c|}
\hline Número de ações & Bagé & Pelotas \\
\hline 2015 & 192 & 455 \\
\hline 2016 & 242 & 373 \\
\hline 2017 & 276 & 388 \\
\hline
\end{tabular}

Os números foram extraídos por intermédio do Boletim Informativo (BI) vinculado ao 
sistema de monitoramento de processos da Procuradoria-Geral do Estado (CPJ) e toma como base os processos judiciais ativos em matéria de saúde no $1^{\circ}$ grau. A área "saúde" do CPJ inclui dois demandados: o Estado/SUS e o IPERGS-saúde (plano de saúde dos servidores públicos do estado). Segundo a PGR, “as ações envolvendo o IPERGS são em número bem pequeno se comparadas às ações do SUS, mas o sistema não tem o filtro para precisar o número de ações para cada demandado" (PGR, 2018).

\section{CONCLUSÃO}

Após a realização do presente estudo, constatou-se que o direito à saúde é um direito social, tendo, portanto, o status de direito fundamental, e que em seu âmbito de abrangência encontram-se questões ligadas tanto à saúde física quanto ao bem-estar mental e até mesmo social. Verificou-se, em seguida, que o direito a medicamentos se trata de um direito prestacional, ou seja, de dimensão positiva, tratando-se, assim, de um direito passível de ser assegurado na via judicial, ainda que se trate de medicamento não previsto em política pública, em razão da força normativa dos preceitos constitucionais e infraconstitucionais.

Na sequência, tratou-se do Recurso Extraordinário nº. 566.471/RN, no qual se projeta uma decisão moderada por parte do Supremo Tribunal Federal, no sentido de que o fornecimento de medicamentos não previstos em política pública não deverá ser encarado como regra, e sim como exceção, podendo ocorrer apenas em casos excepcionais e mediante o cumprimento de requisitos determinados.

Por fim, verificou-se, pela análise dos dados obtidos pela pesquisa jurisprudencial realizada, que os cidadãos das comarcas de Bagé e Pelotas estão tendo seu acesso à justiça, relativamente ao seu direito à saúde, consideravelmente assegurado, no que tange às ações contra os planos de saúde, tendo em vista que o volume de decisões favoráveis aos autores gira em torno de $40 \%$ em relação ao número total de ações judiciais dessa natureza.

Com relação às ações de medicamentos, os dados auferidos pela pesquisa mostraramse insuficientes para uma conclusão segura. Contudo, a figura da Defensoria Pública do Estado mostra-se peça essencial para que a população de baixa renda consiga ter seu acesso à justiça garantido - se o considerarmos, ao menos, em uma visão restritiva, como acesso ao judiciário na busca pela afirmação do direito à saúde. 


\section{REFERÊNCIAS BIBLIOGRÁFICAS}

ÁVILA, Humberto. "Neoconstitucionalismo": entre "ciência do direito" e o "direito da ciência". Revista Eletrônica de Direito do Estado (REDE), Salvador, Instituto Brasileiro de Direito Público, n. 17, jan./fev./mar. 2009. Disponível em: <http://www.direitodoestado.com.br/rede.asp> Acesso em: 10.09.2017.

Humberto. A distinção entre princípios e regras e a redefinição do dever de proporcionalidade. Revista de Direito Administrativo, Rio de Janeiro, n. 215, jan./mar. 1999, p. 151-179. Disponível em: <bibliotecadigital.fgv.br/ojs/index.php/rda /article/download/47313/45714> Acesso em: 14.09.2017.

, Humberto Bergmann. Teoria dos Princípios: da definição à aplicação dos princípios jurídicos. 17. rev. atual. São Paulo: Malheiros, 2016.

BARROSO, Luís Roberto. Curso de Direito Constitucional Contemporâneo: os conceitos fundamentais e a construção do novo modelo. 5 ed. São Paulo: Saraiva, 2015.

, Luís Roberto. Da falta de efetividade à judicialização excessiva: Direito à Saúde, fornecimento gratuito de medicamentos e parâmetros para a atuação judicial. Revista de Direito da Procuradoria Geral do Estado do Rio de Janeiro. Disponível em: <http://www.pge.rj.gov.br/sumario_rev63.asp.>. Acesso em: 12.09.2017.

STRECK, Lenio Luiz; MORAIS, Jose Luiz Bolzan de. Estado Democrático de Direito. In: Comentários à Constituição do Brasil. CANOTILHO, José Joaquim Gomes; MENDES, Gilmar Ferreira; SARLET, Ingo Wolfgang; STRECK, Lenio Luiz (Org.). São Paulo: Saraiva; Almedina, 2013.

COMPARATO, Fábio Konder. Redescobrindo o Espírito Republicano. Revista da AJURIS, v. 32, n. 100, dez. 2005.

DOS SANTOS, Marcus Gouveia. Direitos Sociais: Efetivação, Tutela Judicial e Fixação de Parâmetros para a Intervenção Judicial em Políticas Públicas. Editora Lumen Juris, Rio de Janeiro, 2016.

INSTITUTO BRASILEIRO DE GEOGRAFIA ESTATÍSTICA (IBGE). Pesquisa de orçamentos familiares 2002-2003. Rio de Janeiro: 2004. Disponível em: $<$ https://ww2.ibge.gov.br/home/estatistica/populacao/condicaodevida/pof/2002analise/default _.shtm> Acesso em: 17.02.2018.

INSTITUTO BRASILEIRO DE GEOGRAFIA ESTATÍSTICA (IBGE). Pesquisa Nacional por amostras de Domicílios 1998. Rio de Janeiro, 1998. Disponível em: <https://ww2.ibge.gov.br/home/estatistica/populacao/trabalhoerendimento/pnad98/saude/saud e.pdf> Acesso em: 17.02.2018.

MASSAÚ, Guilherme Camargo; KÖLLING, Gabrielle. A concretização do direito à saúde na perspectiva republicana. Revista de Direito Sanitário, CIDADE v. 12, p. 11-36, 2011. 
Disponível em: < http://www.revistas.usp.br/rdisan/article/viewFile/13247/15064> Acesso em: 22.09.2017.

MOREIRA, Pedro da Silva. O imponderável direito à saúde: uma discussão jurisprudencial a partir do marco teórico de Robert Alexy. Juris Plenum: Direito Administrativo, Caxias do Sul, v. 1, n. 1, p. 51-72, mar. 2014. Disponível em: <www.publicadireito.com.br/artigos/?cod=ca3a9be77f7e8870> Acesso em: 11.09.2017.

NETO, Otávio Balestra. A jurisprudência dos tribunais superiores e o direito à saúde evolução rumo à racionalidade. Revista de Direito Sanitário, São Paulo, v. 16, n. 1, p. 87111, mar./jun. 2015. Disponível em: < http://www.revistas.usp.br/rdisan/article/view/100025> Acesso em: 17.09.2017.

PLANALTO. Decreto no 591 de 6 de julho de 1992 (Pacto Internacional sobre Direitos Econômicos, Sociais e Culturais). Disponível em: <http://www.planalto.gov.br/ ccivil_03/decreto/1990-1994/d0591.htm> Acesso em: 03.03.2018.

SARLET, Ingo Wolfgang. Algumas considerações em torno do conteúdo, eficácia e efetividade do direito à saúde na constituição de 1988. Revista Eletrônica sobre a Reforma do Estado (RERE), Salvador, Instituto Brasileiro de Direito Público, n. 11, set./out./nov. 2007. Disponível em: <http://www.direitodoestado.com.br/rere.asp>. Acesso em: 06.09.2017.

Ingo Wolfgang. Direitos Fundamentais a Prestações Sociais e Crise: algumas aproximações. Espaço Jurídico, Joaçaba, v. 16, p. 459-488, 2015. Disponível em: < editora.unoesc.edu.br/index.php/espacojuridico/article/download/6876/pdf > Acesso em: 07.09.2017.

SILVA, José Afonso da. O Estado Democrático de Direito. Revista de Direito Administrativo, Rio de Janeiro, n. 173, p. 15-24, jul./set. 1988. Disponível em: < http://bibliotecadigital.fgv.br/ojs/index.php/rda/article/viewFile/45920/44126> Acesso em: 18.09.2017.

SILVA, Virgílio Afonso da. O conteúdo essencial dos direitos fundamentais e a eficácia das normas constitucionais. Revista de Direito do Estado, 4, p. 23-51, 2008. Disponível em: <https://constituicao.direito.usp.br/wp-content/.../2006-RDE4-Conteudo_essencial.pdf> Acesso em: 14.09.2017.

, Virgílio Afonso da. O Judiciário e as políticas públicas. In. Cláudio Pereira de Souza Neto \& Daniel Sarmento, Direitos sociais: fundamentação, judicialização e direitos sociais em espécie, p. 587-599, Rio de Janeiro: Lumen Juris, 2008. Disponível em: <https://constituicao.direito.usp.br/wp.../2008-Judiciario_e_politicas_publicas.pdf> Acesso em: 14.09.2017.

, Virgílio Afonso da. O proporcional e o razoável. Revista dos Tribunais, 798, p. 23 50, 2002. Disponível em: <www.revistas.unifacs.br/index.php/redu/ article/viewFile/1495/1179> Acesso em: 15.09.2017.

VENTURA, Miriam et al . Judicialização da saúde, acesso à justiça e a efetividade do direito à saúde. Physis, Rio de Janeiro, v. 20, n. 1, p. 77-100, 2010. Disponível em: 
<http://www.scielo.br/scielo.php?script=sci_arttext\&pid=S01033312010000100006\&lng=en\& $\mathrm{nrm}=$ iso $>$ Acesso em: 17.02.2018. 